NASA Technical Memorandum 106594

AIAA-94-2561

\title{
Measurement of the Coolant Channel Temperatures and Pressures of a Cooled Radial-Inflow Turbine
}

L. Danielle DiCicco and Brent C. Nowlin

Lewis Research Center

Cleveland, Ohio

and

Lizet Tirres

NYMA, Inc.

Engineering Services Division

Cleveland, Ohio

Prepared for the 18th AIAA Aerospace Ground Testing Conference sponsored by the American Institute of Aeronautics and Astronautics Colorado Springs, Colorado, June 20-23, 1994

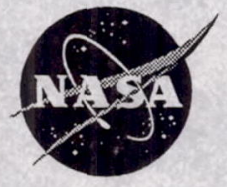

National Aeronautics and Space Administration

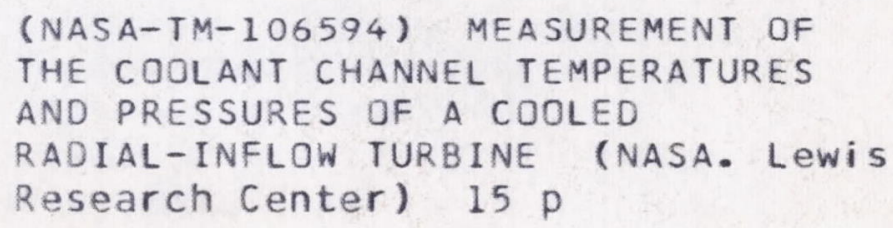




\title{
MEASUREMENT OF THE COOLANT CHANNEL TEMPERATURES AND PRESSURES OF A COOLED RADIAL-INFLOW TURBINE
}

\author{
L. Danielle DiCicco and Brent C. Nowlin \\ National Aeronautics and Space Administration \\ Lewis Research Center \\ Cleveland, Ohio 44135 \\ and \\ Lizet Tirres \\ NYMA, Inc. \\ Engineering Services Division \\ Brook Park, Ohio 44142
}

\begin{abstract}
$\underline{\text { Abstract }}$
Instrumentation has been installed on the surface of a cooled radial-inflow turbine. Thermocouples and miniature integrated sensor pressure transducers were installed to measure steady state coolant temperatures, blade wall temperatures, and coolant pressures. These measurements will eventually be used to determine the heat transfer characteristics of the rotor. This paper will describe the procedures used to install and calibrate the instrumentation, and the testing methods followed. A limited amount of data will compare the measured values to the predicted values.
\end{abstract}

\section{Introduction}

The program to study the performance of a cooled radialinflow turbine represents the pooled efforts of the NASA Lewis Research Center, the Army, and Allison Gas Turbine. NASA and the Army designed the cooled radial stage. Allison Gas Turbine then modified the design and built one stator and two rotors. The two rotors have the same external aerodynamic shape; the only difference is that one rotor has solid blades, while the blades of the other rotor have internal cooling passages. Details of the design and fabrication of the rotors can be found in Refs. 1 and 2. The NASA Lewis Research center was responsible for instrumenting and testing both rotors.

The experiment described in this report was preceded by three other experiments. The first experiment was to collect baseline aerodynamic performance data using the solid rotor. Rakes and actuated survey probes were used to measure total pressure, temperature, and flow angle. Static pressure along the flow path and tip clearances were also measured. ${ }^{3,4}$ No rotating instrumentation was used in this test.

The solid rotor was also used in the second experiment to collect static pressures along the external blade surface. To accomplish this objective, trenches were machined into the surface of the rotor blades. Stainless steel tubing was epoxied into these trenches, creating 36 pressure taps along three streamlines. To measure blade surface static pressures while rotating, static pressures were transferred pneumatically to a stationary transducer that was part of a special Rotating Data Package. Details of this experiment are documented in Refs. 4 and 5.

In the third experiment, an aerodynamic performance evaluation of the cooled rotor was conducted similarly to that of the solid rotor during the first experiment, Ref. 6 . No instrumentation was installed on the surface of the cooled rotor for this aerodynamic performance test.

This report will describe the instrumentation techniques used in an experiment to determine the heat transfer characteristics of the cooled radial-inflow turbine. In this experiment thermocouples and miniature integrated sensor pressure transducers were installed directly onto the rotor blade surfaces. Measurements were recorded while operating on and off design point conditions. Methods used to install and calibrate the instrumentation will be discussed in detail. A limited amount of data will be presented.

\section{$\underline{\text { Facility }}$}

All testing was conducted at the NASA Lewis Small Engine Components Turbine Facility (SECTF). This unique, continuous-flow facility is dedicated to studying the performance of turbines designed for small gas turbine engines. The main components of the facility shown in Figure 1 include inlet and exhaust piping, a natural gas combustor, an in-line torquemeter, an eddy current dynamometer, and a liquid nitrogen heat exchanger. Turbine inlet pressures can range up to $40 \mathrm{psia}(2.7 \mathrm{~atm})$, and exit pressures can reach 2 psia ( 0.15 $\mathrm{atm})$. The natural gas combustor can raise the turbine inlet temperature up to a maximum of $800 \mathrm{~F}(700 \mathrm{~K})$. The power and torque limits of the facility are $5124 \mathrm{in}-\operatorname{lbf}(29.3 \mathrm{~N}-\mathrm{m})$ and $1250 \mathrm{HP}(932 \mathrm{~kW})$, respectively. The liquid nitrogen heat exchanger is used to chill the air to be used as coolant for cooled turbines. A more thorough description of the facility capabilities can be found in Refs. 6 and 7 . 
Research Hardware and Test Requirements

The cooled radial turbine was used in this experiment, and a photograph taken before the blades were instrumented can be seen in Figure 2. Figure 3 is an illustration of the internal cooling passage geometry. Chilled air fills an inducer behind the rotor backface, passes through the coolant channels, and is discharged into the primary airflow through slots in the trailing edge of the blades. To determine the heat transfer characteristics of this turbine, eight sites along the coolant flow path were selected for instrumentation. Those eight sites are marked in Figure 4.

Three conditions were considered when choosing the instrumentation to measure temperatures and pressures: 1) the operating environment, 2) the turbine geometry, and 3) the number of test configurations needed to complete the data set. The instrumentation system used in this experiment was designed to meet the research requirements despite the constraints described below.

The operating environment was harsh. Any instrumentation installed on the turbine blades would have to survive both high temperatures and large centrifugal loading. Temperatures would range up to $400 \mathrm{~F}(477 \mathrm{~K})$. Since the experimental design point speed was $19,475 \mathrm{rpm}$, centrifugal loads would range from $39,838 \mathrm{G}$ at the trailing edge hub radius to 71,103 $\mathrm{G}$ at the leading edge tip radius.

The turbine geometry itself factored into the selection of instrumentation, and proved to be one of the biggest challenges faced. When installing any type of instrumentation onto an aerodynamic surface, the amount of disturbance caused by the sensor and the sensor's electrical leads should be minimized. However, the techniques used to install instrumentation to achieve this goal are greatly dependent on the hardware geometry. Techniques used to install low-profile sensors on axial turbine and compressor blades could not be used in this case because of the large size of the radial turbine and the complex shape of its blades. The blades could not be instrumented separately, either, since the rotor was cast as one unit.

Another technique often used to preserve the integrity of an aerodynamic surface is to machine trenches into the surface of the blade. The sensor leads could then be epoxied into these trenches, leaving the aerodynamic surface smooth. Again, this technique could not be used in this experiment. The rotor blades were hollow and the wall thicknesses were both thin and irregular. The risk of breaking through a wall while machining a trench was too great. Wall thickness measurements taken later during the instrumentation process showed that wall thicknesses varied up to 0.114 in $(0.045 \mathrm{~cm})$ between sites on the pressure side, and up to 0.043 in $(0.017 \mathrm{~cm})$ between sites on suction side. This is just one indication of the difficulties of casting a cooled radial turbine.

The material of the rotor also factored into the design of the instrumentation. The radial turbine was fabricated of MAR M247, a very hard material to machine with conventional carbide tools. Any probe ports would have to be electron discharge machined. The site location would depend on the ability to reach it with an electrode.

The final issue considered when designing the instrumentation scheme was the number of test configurations needed to complete the data set. This reduced to the question of whether or not the pressure measurements should be transferred from the rotating environment pneumatically or electrically. During the second experiment described in the Introduction, onboard pressure measurements were transferred to the stationary environment pneumatically, using a special Rotating Data Package. That package was capable of measuring 36 rotating pressures, but was not capable of transferring any temperature measurements due to modifications. Those modifications were to provide an indexing feature that was not originally supplied. ${ }^{5}$ To transfer pressure signals electrically, individual pressure transducers would have to be mounted directly onto the blades. The electrical signals for both the pressure and temperature sensors could then be transferred simultaneously to the stationary environment using a slip ring.

\section{Instrumentation Selection. Installation, and Calibration}

The main components of the instrumentation system were the slip ring, pressure transducers, thermocouples, and resistance temperature devices. This instrumentation was integrated into the facility's ESCORT steady state data acquisition system. ${ }^{7}$

\section{Selection}

A 100 channel slip ring system was chosen over reusing/ modifying the Rotating Data Package. The number of available channels limited the amount of instrumentation that could be installed on the rotor. Given this constraint, eight pressure transducers, 31 thermocouples, and three platinum resistance temperature devices (RTD's) were chosen.

Type K Chromel-Alumel thermocouples were chosen to measure the temperature of the blade walls and of the coolant. Thermocouples were chosen over other temperature measuring devices because of their small size and their comparatively simple installation procedure. Resistance temperature devices were used to measure the cold junction temperature. The cold junction was made at a pair of mating printed curcuit boards.

Since the slip ring would be transmitting pressure signals electrically and not pneumatically, each pressure transducer would have to be mounted on the turbine blades. The pressure transducers selected were 0 - 50 psia $(0-3.4 \mathrm{~atm})$ miniature integrated sensor transducers. In our search, this was the smallest transducer commercially available that could withstand operating temperatures up to $400 \mathrm{~F}(477 \mathrm{~K})$.

\section{Installation}

To instrument the coolant passages, ports had to be electron discharge machined through the blade walls, Figure 5. The thermocouples and pressure transducers could then be installed into these ports. The sensor leads were epoxied directly onto the exterior blade surfaces and were routed 
through slots into the rotor hub. The epoxy used was developed to mount strain gages, special sensors, and leadwires onto metal substrates, and had been used in similar applications in the past. After being routed into the rotor hub, the leads were then terminated on pins of a printed circuit board. This printed circuit board was bolted to the rotor hub, and rotated at turbine speed. The slip ring mated to the circuit board and transferred the signals from the rotating environment to the stationary environment.

Thirty-one Chromel-Alumel (Type K) thermocouples were installed at the sites marked in Figure 4. Each wire was 30 AWG $(0.010$ inch, $0.025 \mathrm{~cm})$ and was Kapton insulated. Although both Kapton and Teflon (common wire insulators) would withstand the high temperatures, Kapton was chosen since it would bond better with the epoxy. Teflon was also undesirable since it had the tendency to cold-flow off the wires under centrifugal loading. ${ }^{8}$

In order to be able to determine the rate of heat transfer across the blade wall, thermocouples had to be installed to measure the coolant temperature, the interior wall temperature, and the exterior wall temperature. Figure 6 shows the distribution of the thermocouples along the internal coolant flow path. Figure 7 shows a cross sectional view of the thermocouples installed at Site 1 . Ports $0.040 \mathrm{inch}(0.102 \mathrm{~cm})$ in diameter were machined completely through the blade wall. The thermocouples were placed in the middle of the coolant channel to measure coolant temperature. To measure the interior wall temperature, a ports 0.040 inch $(0.102 \mathrm{~cm})$ were machined into the blade wall, but did not break through into the channel. This would ensure that the thermocouple would be measuring the blade metal temperature, and would prevent the thermocouple itself from perturbing the coolant flow. To measure the exterior wall temperature, the thermocouple junction was epoxied directly onto the surface of the blade. A sketch of the thermocouple installation can be found in Figure 8.

Eight pressure transducers were mounted at the sites shown in Figure 9, and were used to measure the coolant pressure. Each transducer had four 36 AWG $(0.005$ inch, $0.013 \mathrm{~cm})$ Teflon insulated leads. Since the leads were insulated with Teflon, special procedures were used to mount the leads to the rotor surface. The leads were first roughened, and then were covered with a thin strip of fiberglass cloth impregnated with the epoxy. Figure 10 shows how the pressure transducers were mounted. To provide isolation from strain and vibration, the transducers were epoxied on one end only and floated on a layer of silicone rubber. Straining the pressure sensitive area of the transducer would cause a false pressure measurement. The perforated shim was used for added mounting support. These techniques were recommended in Ref. 9.

Finally, the three resistance temperature devices were mounted to the printed circuit board. Figure 11 shows the completely instrumented rotor with the circuit board installed on the hub. Since the junctions between the thermocouple alloy wire and the copper leads were made at the printed circuit board, the RTD's were used to measure the cold junction reference temperature. A thermally conductive epoxy secured the RTD's to the circuit board.

\section{Calibration}

Integrated sensor pressure transducers are traditionally used for measuring unsteady pressures. Because these transducers would be used for measuring steady state pressures in this experiment, special attention was given to their calibration.

Before the transducers were installed on the rotor, they were calibrated not only for a range of pressures, but for a range of temperatures, as well. Transducer output was measured from 0 to $100 \%$ full scale in $10 \%$ increments, and values of the transducer slope, sensitivity, and zero offset were determined. This was done for temperatures ranging from ambient to $400 \mathrm{~F}(477 \mathrm{~K})$. A sample of the calibration data can be found in Figures 12 through 14.

As can be seen from the calibration curves, transducer characteristics varied with temperature-particularly, the zero offset. A method described in Ref. 10 was used to compensate for these thermal effects. Since the transducer bridge current varied only with temperature, a $2.5 \mathrm{ohm}$ sense resistor was added across the bridge to measure bridge current, Figure 15 . The voltage across this sense resistor varied only with temperature and was recorded during the same calibration described above, Figure 16. The technique described in Ref. 10 used the sense resistor calibration data to create a hardwired compensation circuit. In this experiment, however, thermal compensation was made in real time using the data acquisition system software. The temperature of the transducer bridge was determined by measuring the voltage across the sense resistor and using the data obtained from the calibration. Once the bridge temperature was known, transducer slope and zerooffset was found from the calibration data. This calibration data was represented in the data reduction program either as a curve fit of the calibration data or a table of the calibration data that would be linearly interpolated in real time.

\section{$\underline{\text { Results }}$}

Preparation for this test was extensive; over 1000 hours were required to install the instrumentation on the rotor, and over 160 hours to install the rotor and the slip ring into the test rig. Prior to rotation, many checks were made to ensure electrical continuity to the instrumentation. Mock tests were also conducted to verify the data reduction software. After the static tests, rotating tests were conducted to verify the assembly of the rotor into the rig and the health of the facility subsystems.

The design point conditions for this radial turbine can be found in Figure 17. Predicted values for the coolant temperatures and pressures were generated using the $\mathrm{ADAPCO}$ heat transfer analysis code. It must be noted that an inlet temperature of $600 \mathrm{~F}(588 \mathrm{~K})$ was used to generate the predictions. Since there were no commercially available miniature pres- 
sure transducers that would survive such high temperatures, the testing conditions were scaled down.

The midstream coolant temperatures were compared with the predicted results, and can be found in Figure 18. Comparison of the temperature measurements with the predicted results show the expected trends, despite some differences in the absolute values of the temperatures. These differences can be attributed to the mismatch between the test conditions and the conditions used to generate the predictions. Coolant temperature data was collected at three rotational speeds. The effect of the rotational speed on the coolant temperature could only be seen near the inlet, at sites 1 and 2 .

The temperature difference across the blade walls at site 1 can be seen in Figure 19. The effectiveness of the coolant flow through the channel can be seen in the difference between the suction side wall temperatures and the pressure side wall temperatures. The pressure side wall temperatures are consistently lower than the suction side wall temperatures due to the movement of the blade passage relative to the coolant flow.

Figure 20 shows pressure transducer measurements at offdesign conditions compared to the predicted values. These measurements were taken at the conditions tabulated in Figure 21. This figure shows pressure measurements near expected values, indicating that the temperature correction algorithm was successful. The difference between the calculated pressures and the measured pressures can be attributed to the mismatch in conditions. Turbine rotational speed has a more noticeable effect at sites near the leading edge. Attempts were made to collect design point measurements of the coolant, but as the turbine inlet temperature increased, signals from all but two of the pressure transducers were lost. Post failure analysis and examination showed that the silicone rubber holding six of the transducers failed, causing either all or part of those transducers to be torn from the rotor.

\section{Conclusions and Recommendations}

The techniques used to install and calibrate thermocouples and pressure transducers on a cooled radial inflow turbine were presented in detail. This instrumentation was used to measure the temperature and pressure of air in the interior cooling passages of the turbine while rotating at design point conditions. Measurements were obtained and compared to predicted values. Both the temperature measurements along the coolant flowpath and across the blade walls showed the expected trends.

To extend the pressure transducer life, several modifications to the installation procedure are recommended. Rather than floating the transducer on a layer of silicone rubber, the transducer should be epoxied directly to the blade surface. To account for any prestrain of the transducer diaphragm, the entire instrumented rotor should be calibrated for a series of pressures and temperatures. Compensation of the pressure measurements would also have to be made to account for rotor flowering and consequent strain of the diaphragm during operation.

\section{Bibliography}

1. Snyder, P. H., and Roelke, R. J., "The Design of an AirCooled Metallic High Temperature Radial Turbine," AIAA 88-2872, 1988.

2. Snyder, P. H., "Cooled High-Temperature Radial Turbine Program-II Final Report,” NASA CR-189122, 1992.

3. Tirres, L., "A Comparison of the Analytical and Experimental Performance of the Solid Version of a Cooled Radial Turbine," AIAA-91-2133, 1991.

4. Tirres, L., "A Comparison of the Calculated and Experimental Off-Design Performance of a Radial Flow Turbine," AIAA-92-3069, 1992.

5. DiCicco, L. D., Nowlin, B. C., and Tirres, L., "Description of a Pressure Measurement Technique for Obtaining Surface Static Pressures of a Radial Turbine," AIAA92-4006, 1992.

6. Tirres, L., DiCicco, L. D., and Nowlin, B. C., "Experimental Evaluation of a Cooled Radial-Inflow Turbine," AIAA-93-1795, 1993.

7. Nowlin, B. C., and Verhoff, V. G., "Small Engine Components Test Facility Turbine Testing Cell," AIAA-882963.

8. DeRose, R., "Application for Strain Gauges and Thermocouples to Rotating and Stationary Hardware," Von Karman Institute for Fluid Dynamics, Lecture Series 1981-7, Measurement Techniques in Turbomachines, May 18-22, 1981.

9. Grant, H. P., and Lanati, G. A., "Instrumentation for Measuring the Dynamic Pressure on Rotating Compressor Blades," NASA CR-159499.

10. Cherrett, M. A., "Temperature Error Compensation Applied to Pressure Measurements Taken with Miniature Semiconductor Pressure Transducers in a High-Speed Research Compressor," Royal Aerospace Establishment, Technical Memorandum P 1192, 1990. 


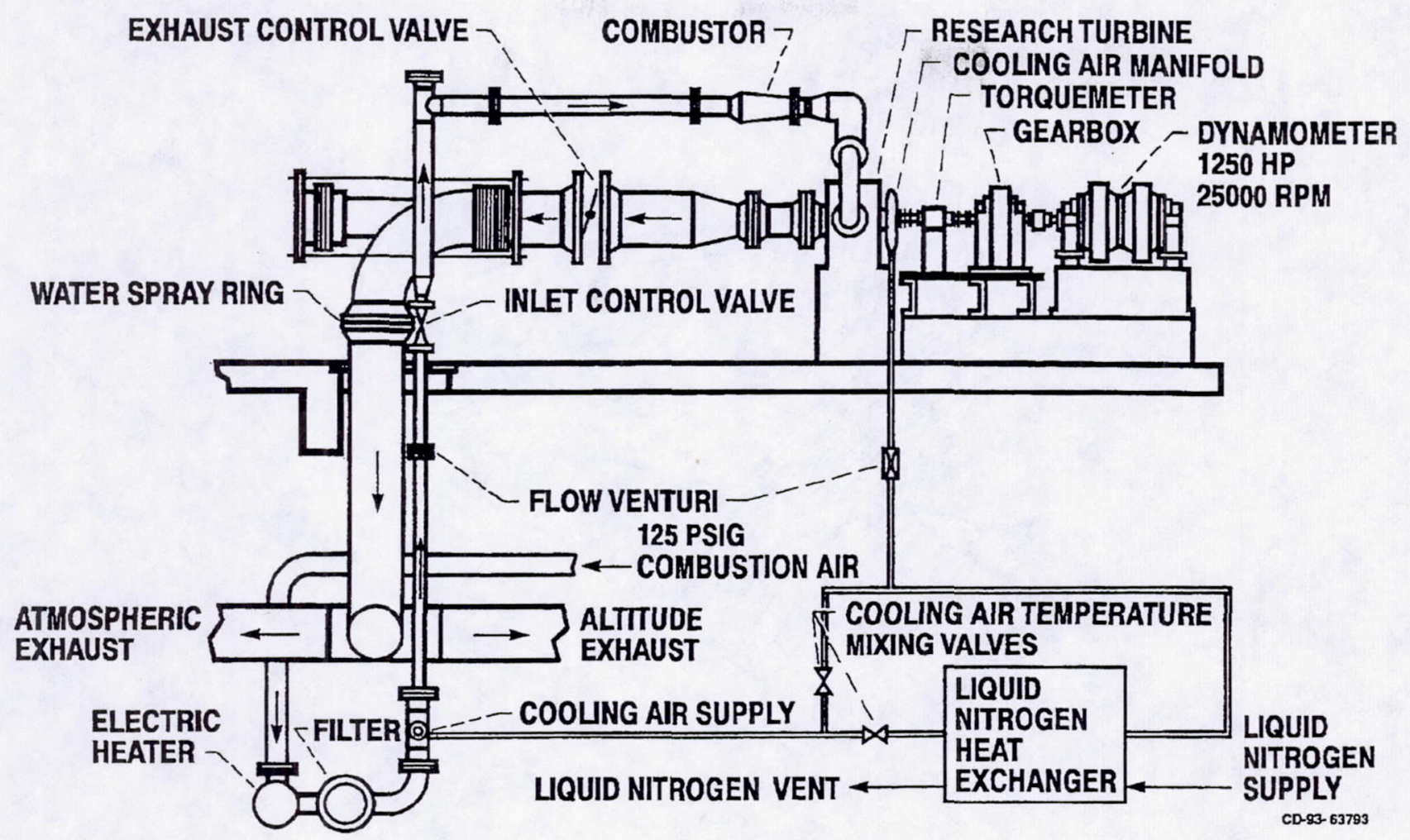

Figure 1.-Small engine components turbine facility schematic.

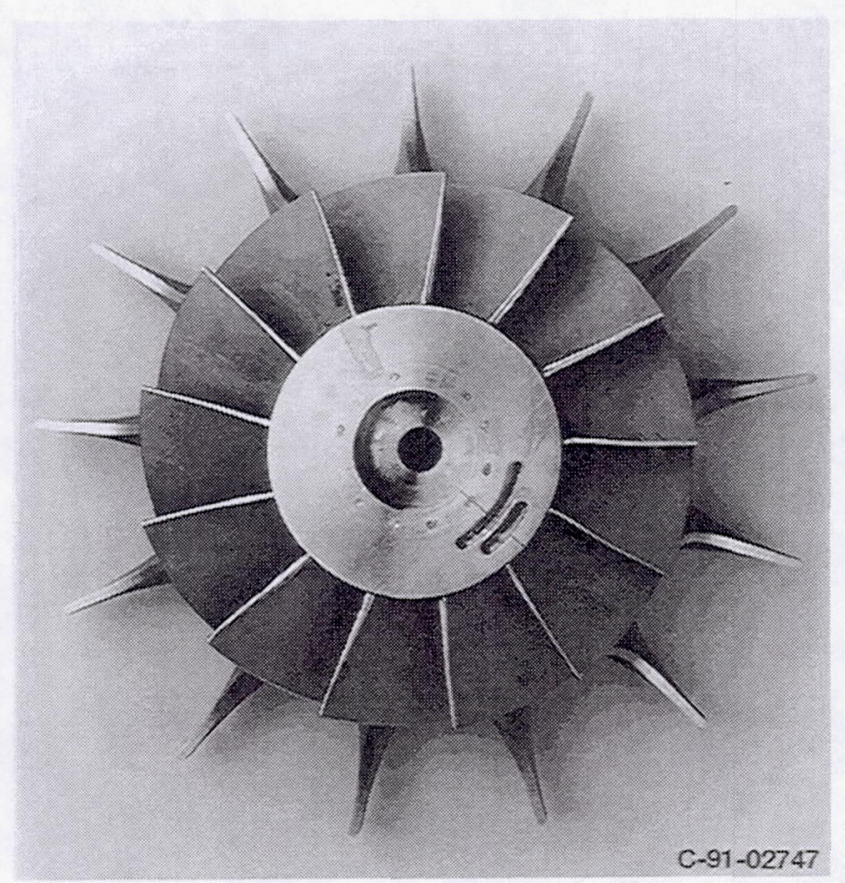

Figure 2.-Cooled radial-inflow turbine before instrumentation. 


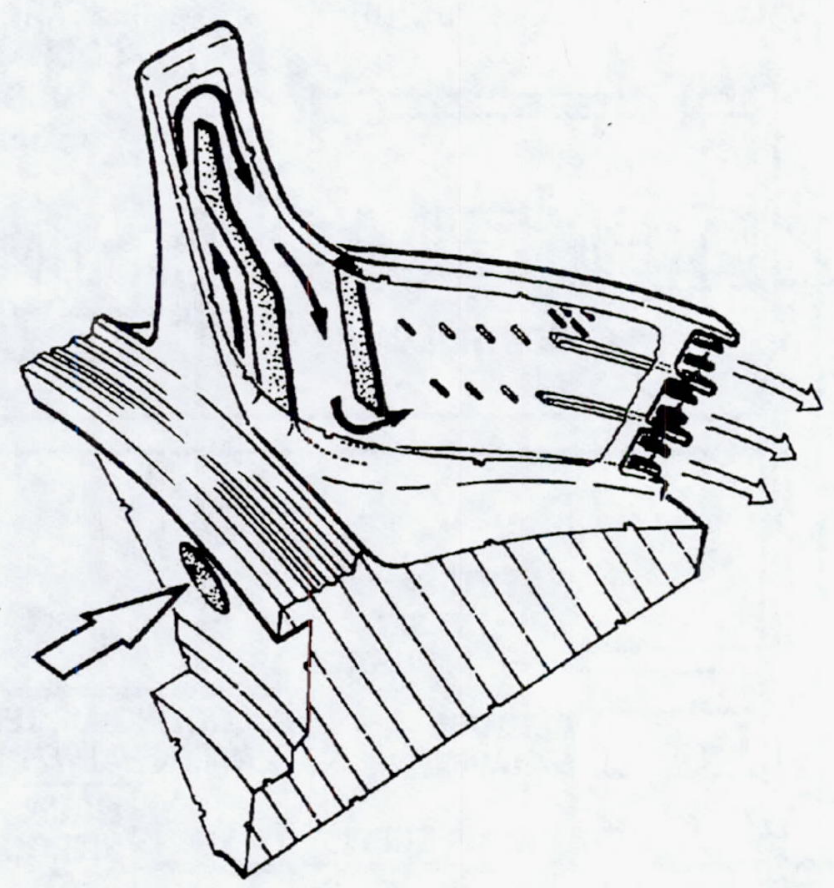

Figure 3.-Internal coolant passage geometry.

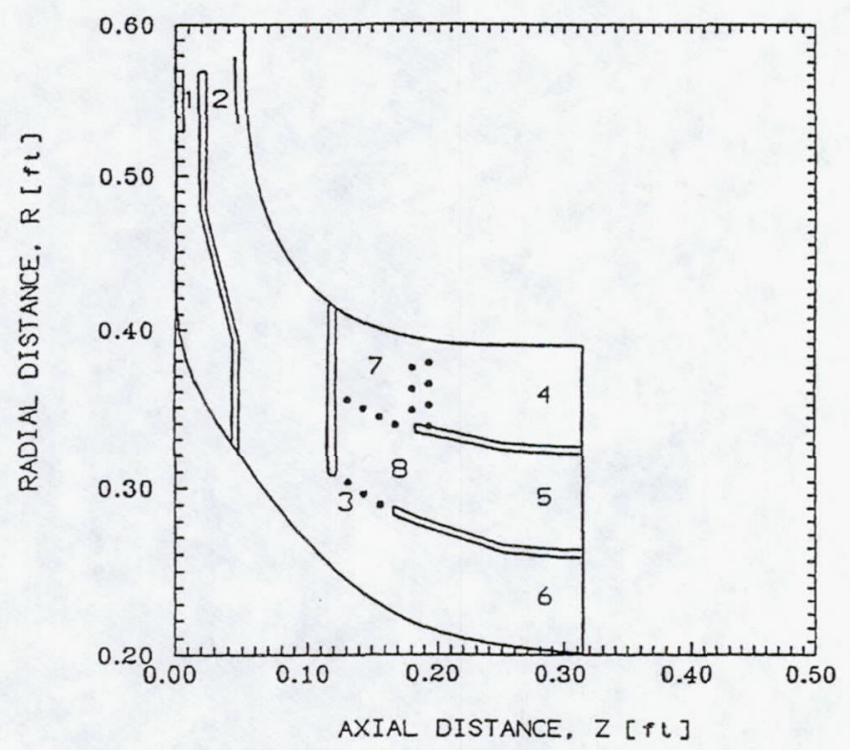

Figure 4.--Instrumentation site locations. 


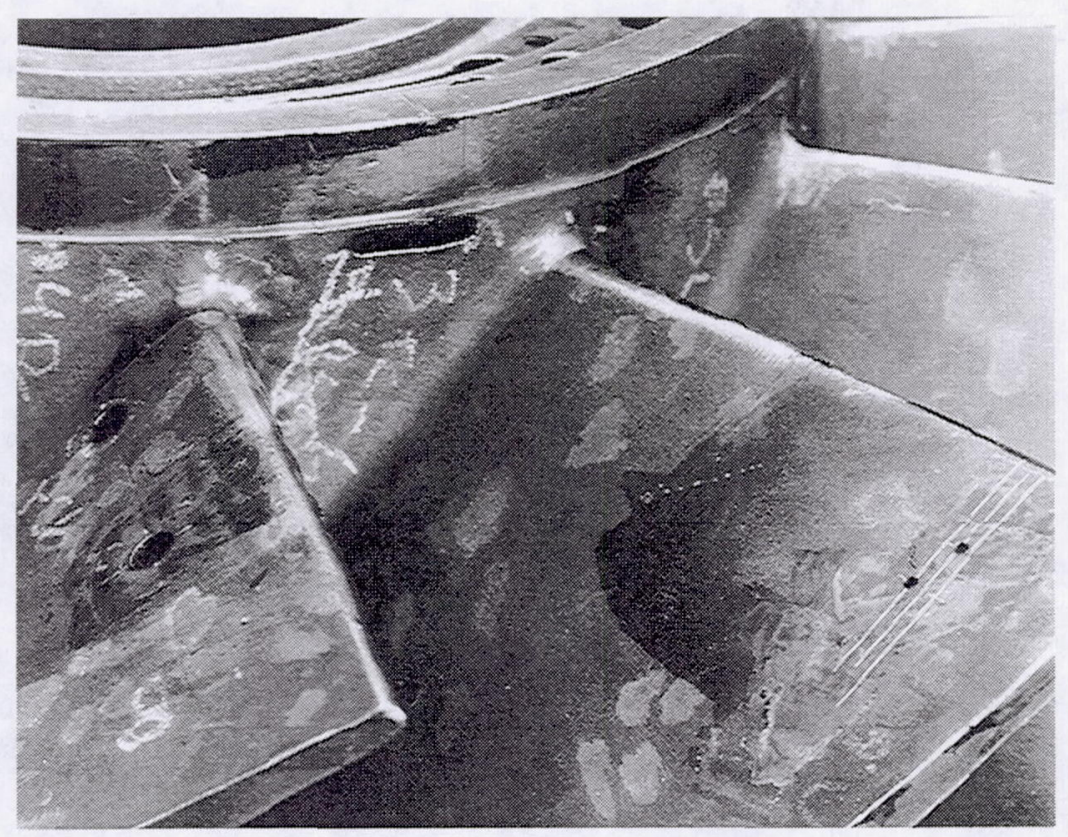

Figure 5.-Ports machined into the blade trailing edges for instrumentation.

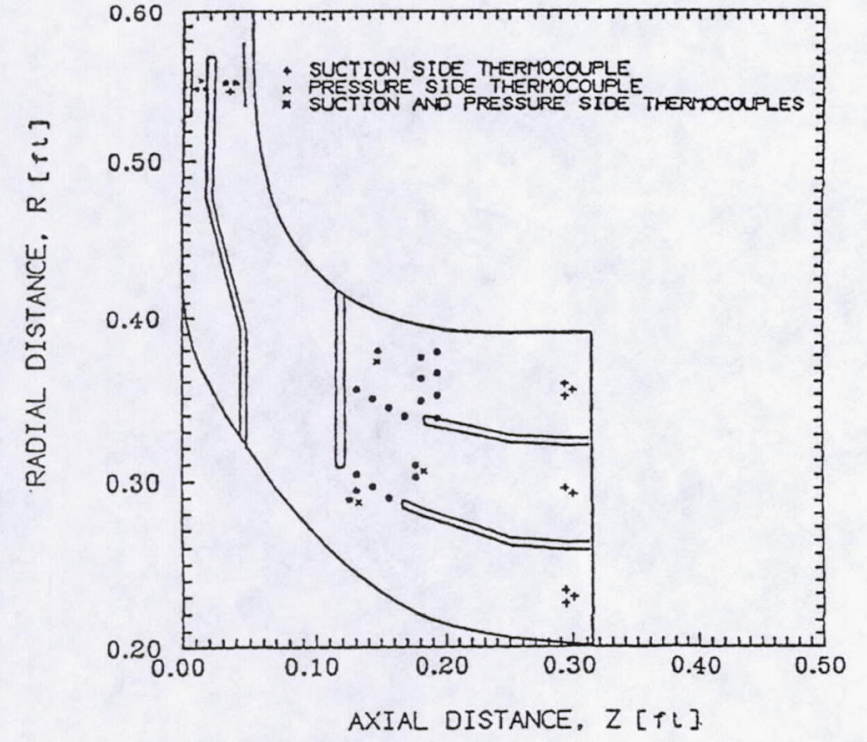

Figure 6.-Thermocouple locations.
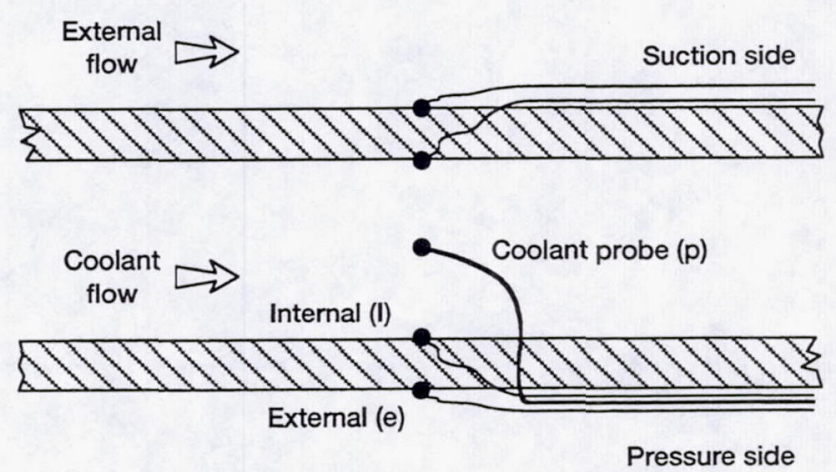

Figure 7.-Coolant passage cross section showing approximate placement of thermocouples at Site 1. 
0.040 in. diameter hole machined through blade wall into coolant channel-for thermocouple to measure coolant temperature

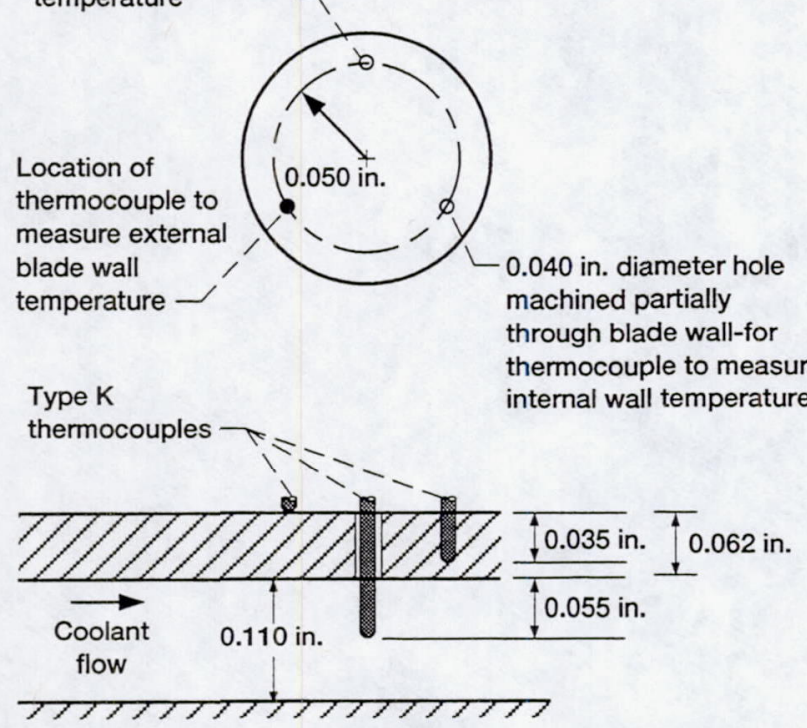

Figure 8.-Detail of pressure side thermocouple installation.

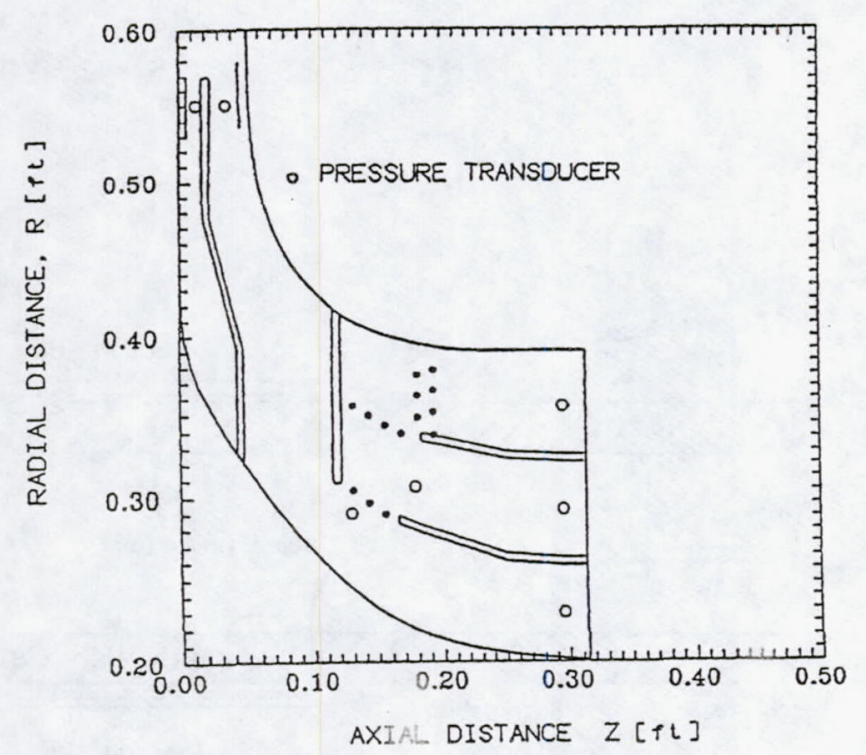

Figure 9.-Pressure transducer locations.

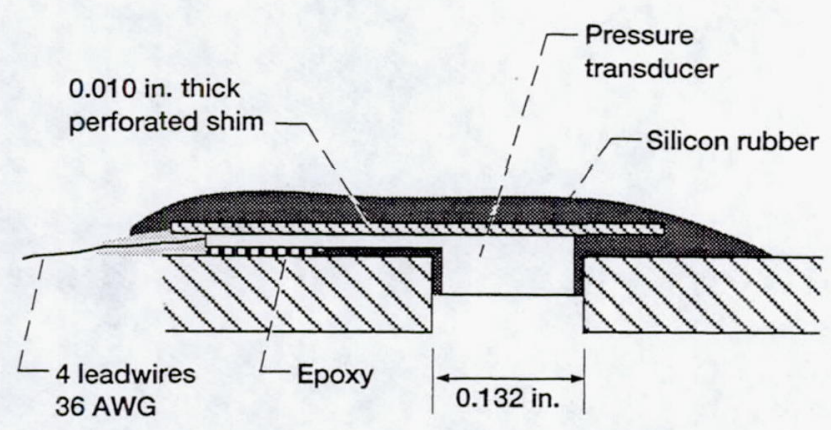

Figure 10.-Pressure transducer installation.

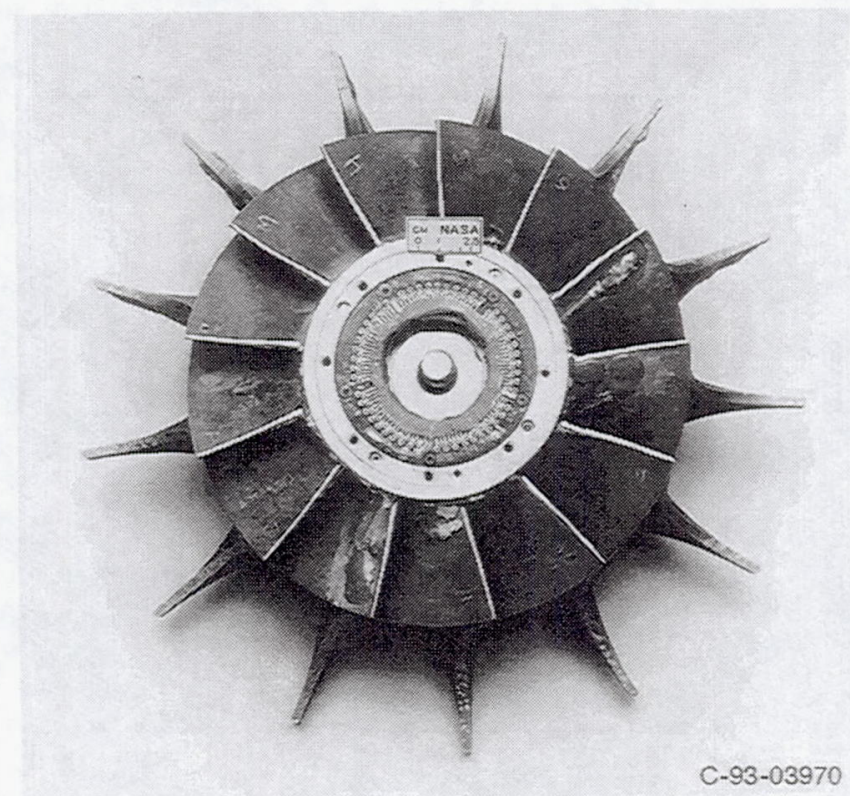

Figure 11.-Instrumented cooled radial-inflow turbine with printed circuit board. 


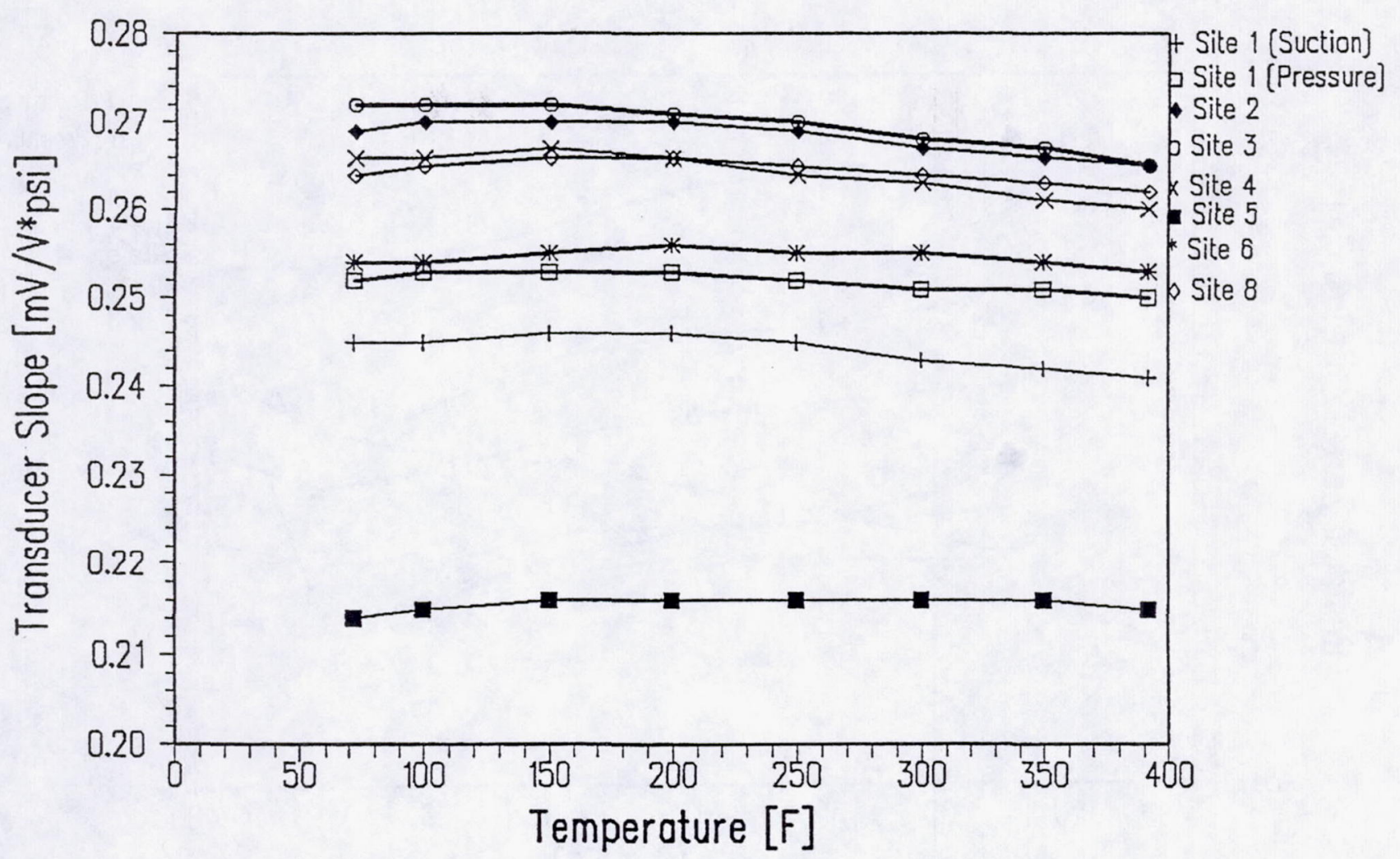

Figure 12.-Pressure transducer calibration data, transducer slope versus temperature.

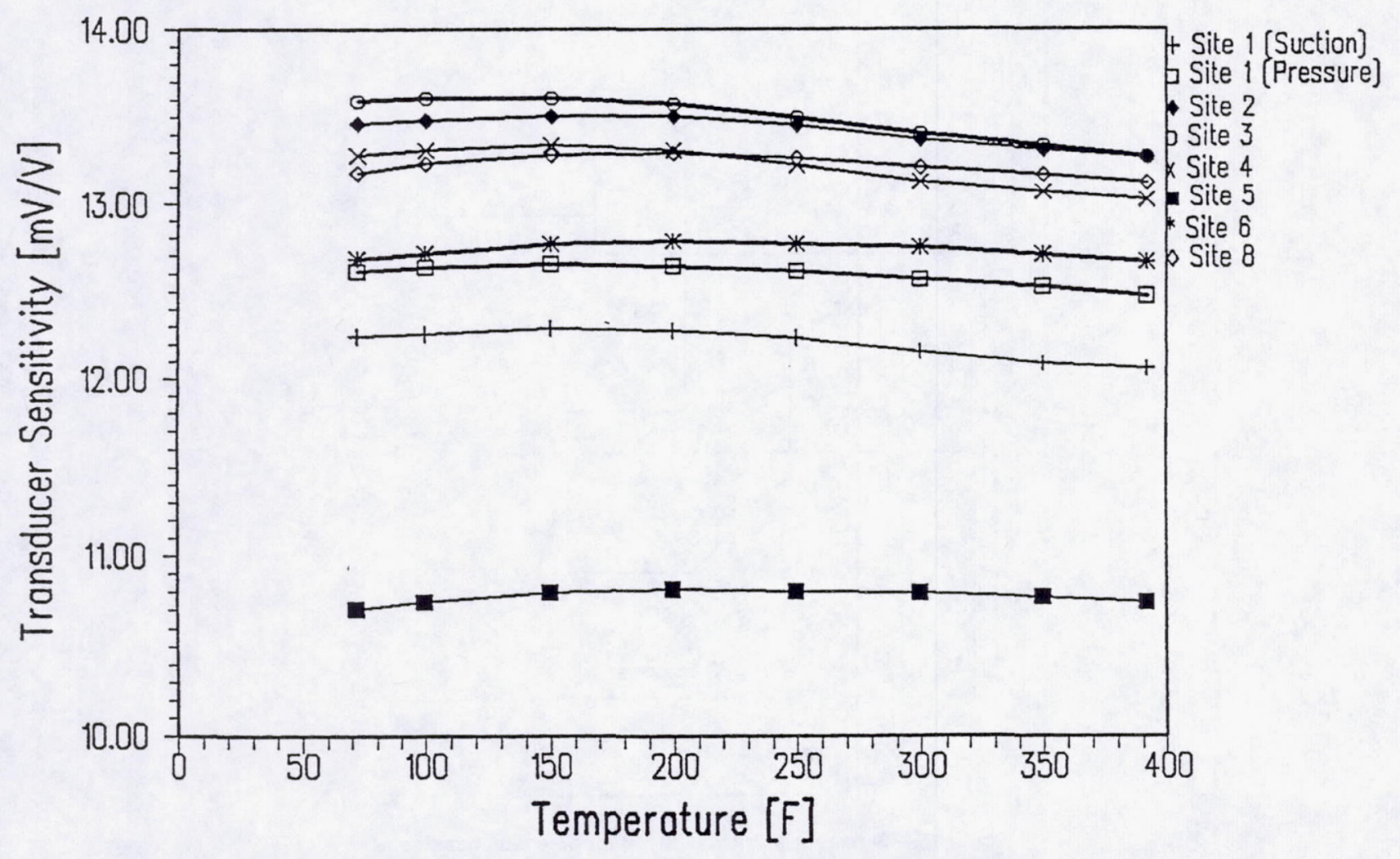

Figure 13.-Pressure transducer calibration data, transducer sensitivity versus temperature. 


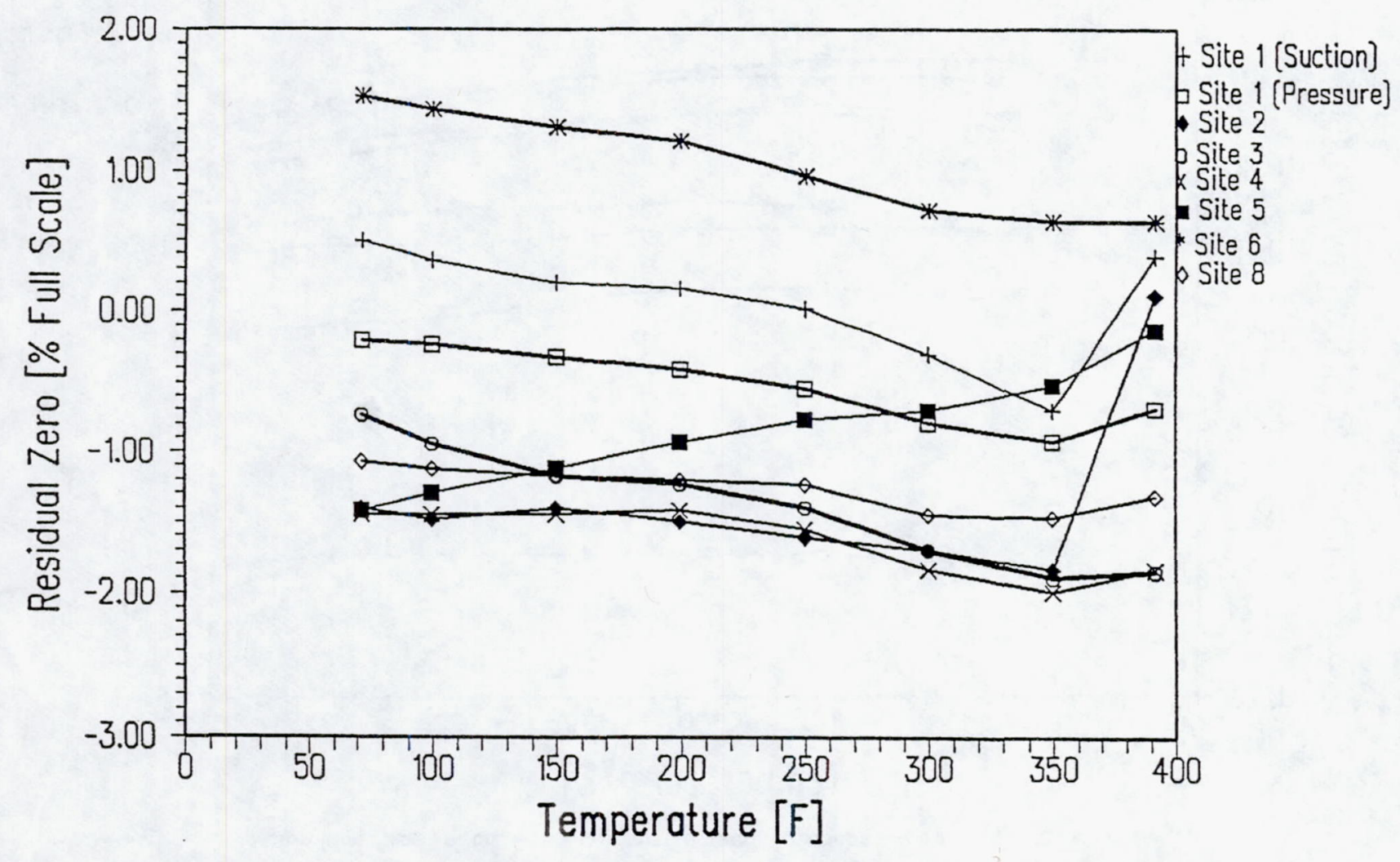

Figure 14.-Pressure transducer calibration data, zero offset versus temperature.

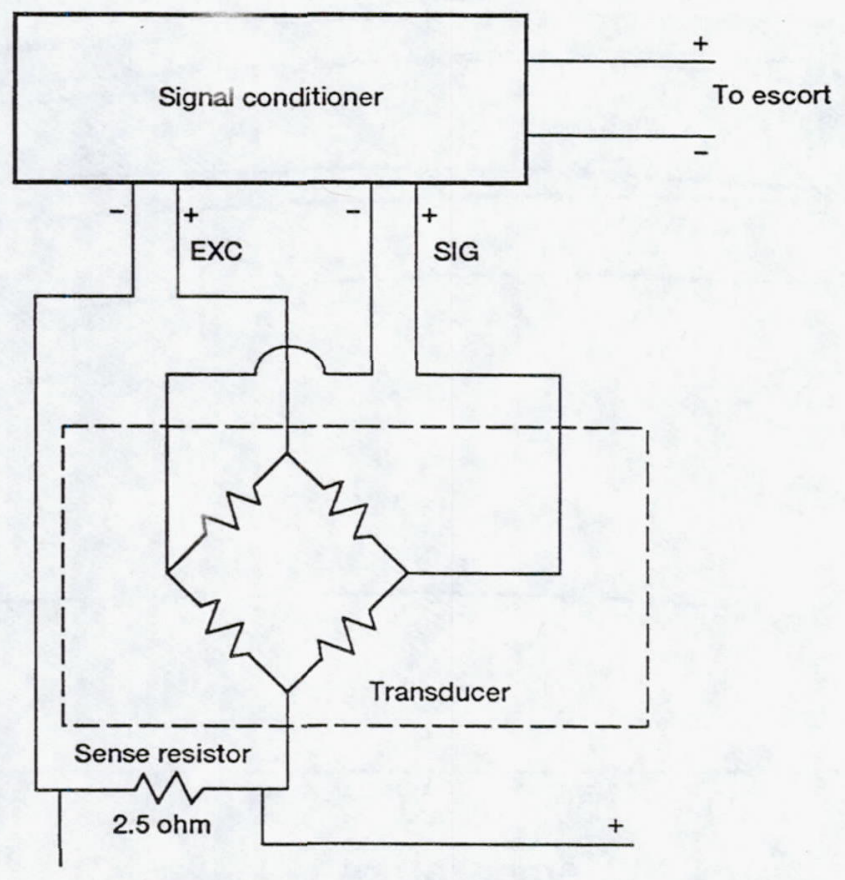

Figure 15.-Sense resistor circuit used for pressure measurement temperature compensation. 


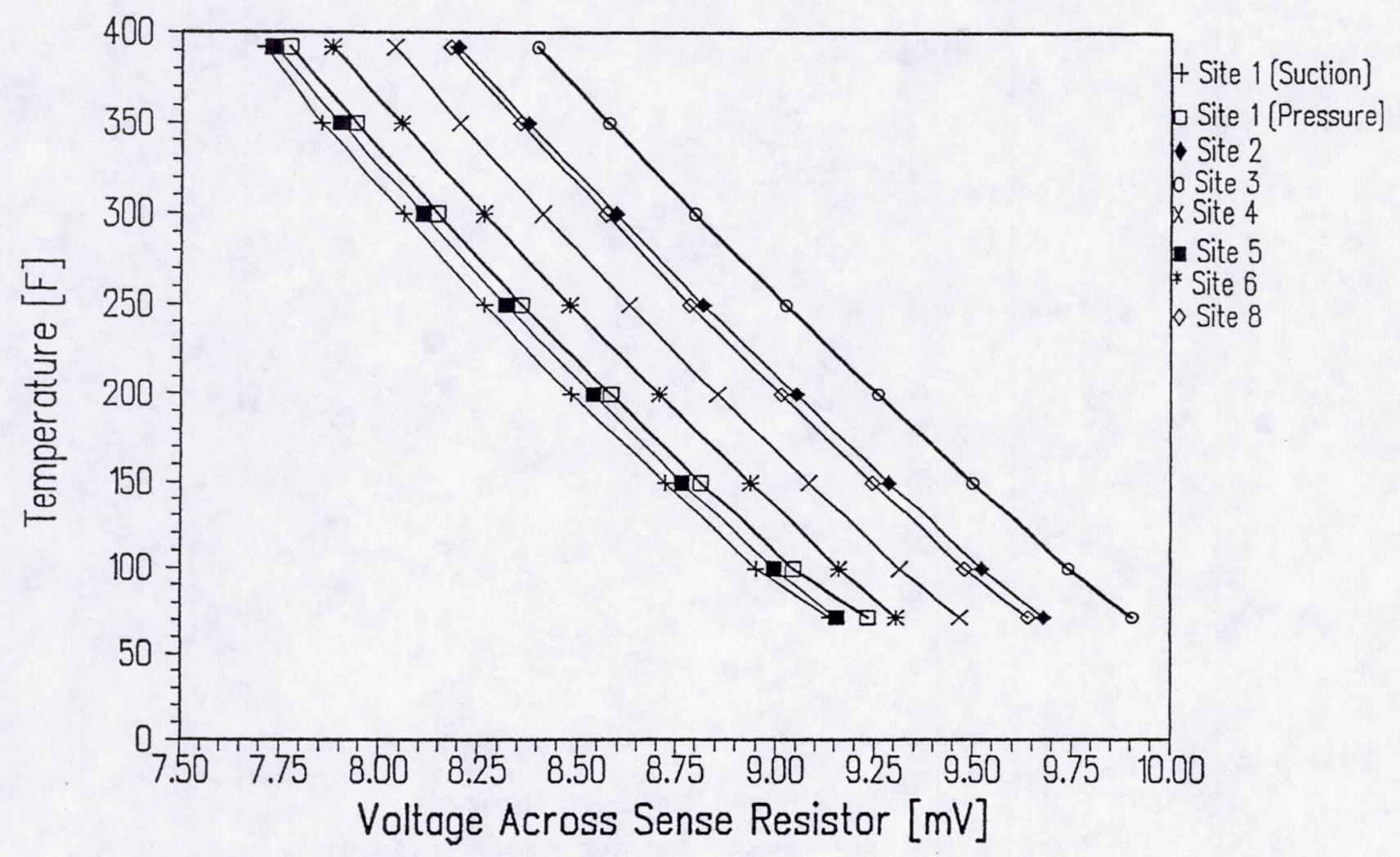

Figure 16.-Pressure transducer calibration data, temperature versus voltage across sense resistor.

\begin{tabular}{|l|l|}
\hline Inlet temperature & $400.0 \mathrm{~F}(477.6 \mathrm{~K})$ \\
Inlet pressure & $30.0 \mathrm{psia}(206.8 \mathrm{kPa})$ \\
Coolant-to-primary temperature ratio & 0.445 \\
Inlet total-to-exit total pressure ratio & 4.0 \\
Coolant-to-primary mass flow ratio & 0.043 \\
Rotational speed & $19,475 \mathrm{rpm}$ \\
\hline
\end{tabular}

Figure 17.-Design point conditions. 


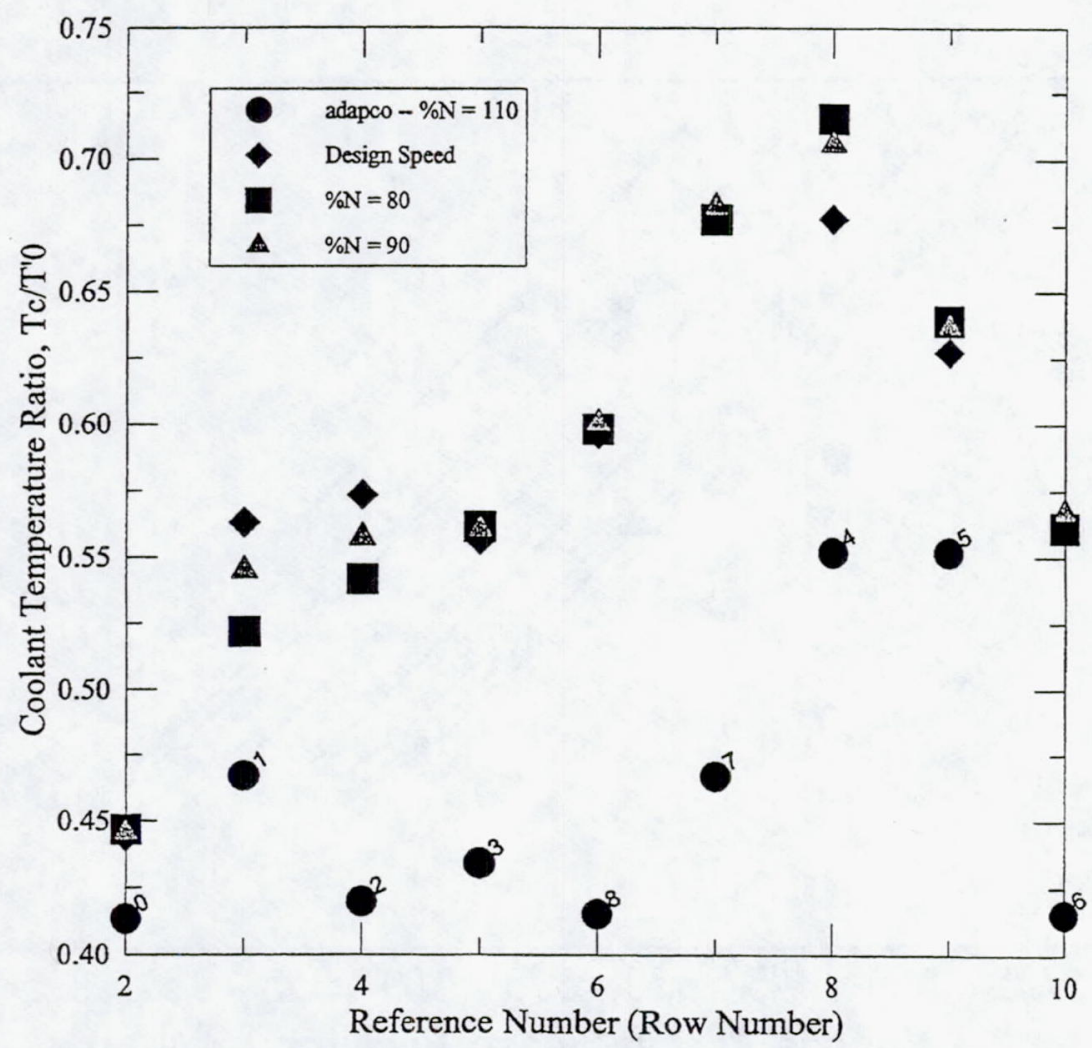

Figure 18.-Comparison of measured and predicted midstream coolant temperatures.

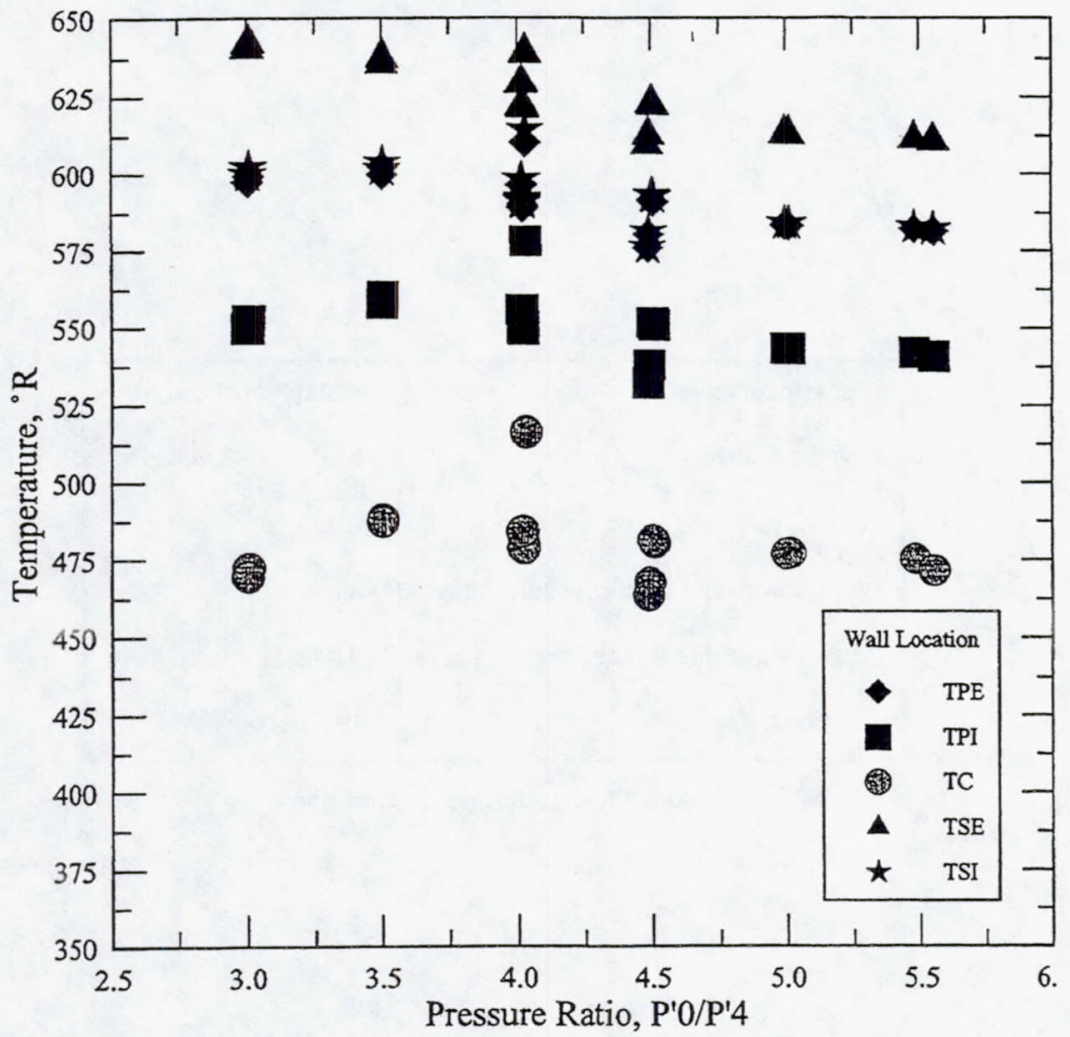

Figure 19.-Blade wall temperature measurements at Site 1. 


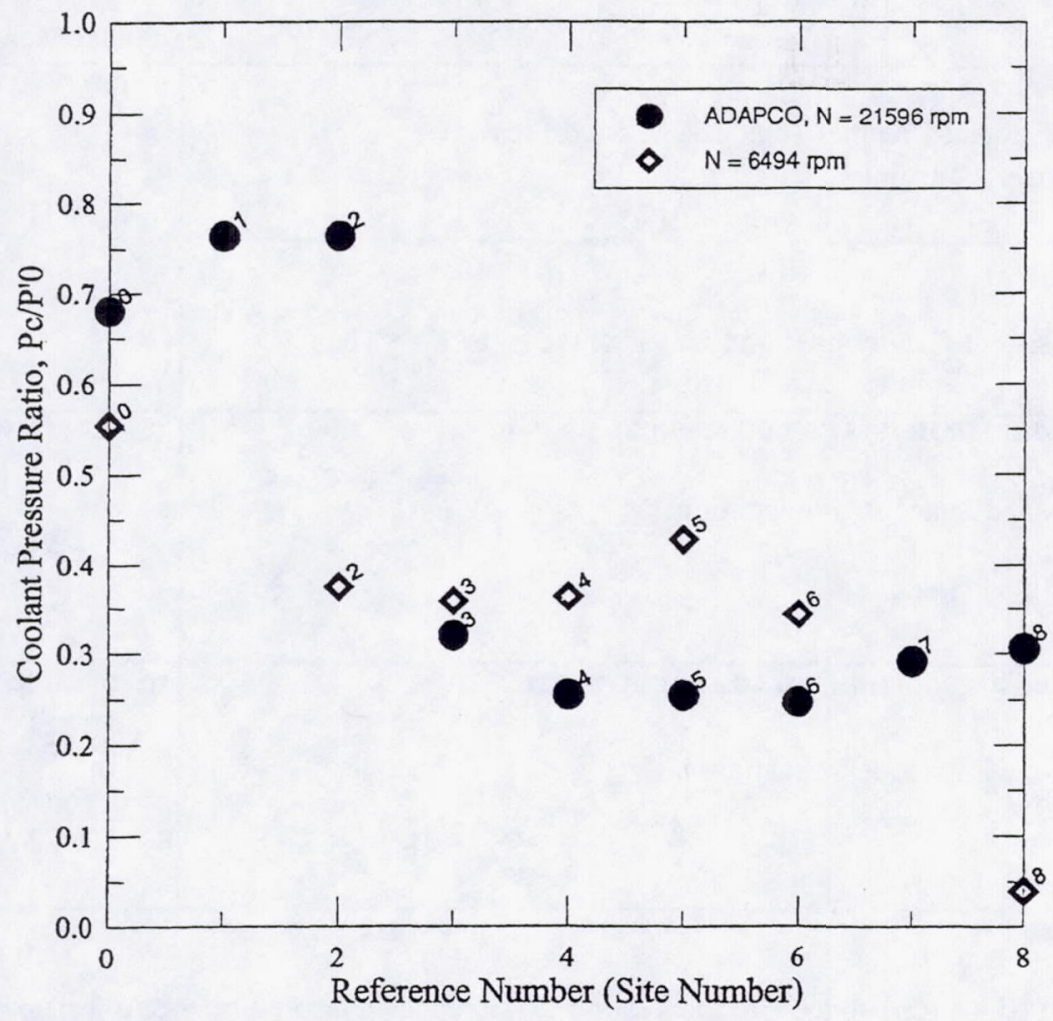

Figure 20.-Comparison of predicted pressures with measured pressures at off design conditions.

\begin{tabular}{|l|l|}
\hline Inlet temperature & $293.2 \mathrm{~F}(418.2 \mathrm{~K})$ \\
Inlet pressure & $29.7 \mathrm{psia}(204.8 \mathrm{KPa})$ \\
Coolant-to-primary temperature ratio & 0.653 \\
Inlet total-to-exit total pressure ratio & 2.5 \\
Coolant-to-primary mass flow ratio & 0.0406 \\
Rotational speed & $6494 \mathrm{rpm}$ \\
\hline
\end{tabular}

Figure 21.-Off design conditions. 
Public reporting burden for this collection of information is estimated to average 1 hour per response, including the time for reviewing instructions, searching existing data sources, gathering and maintaining the data needed, and completing and reviewing the collection of information. Send comments regarding this burden estimate or any other aspect of this collection of information, including suggestions for reducing this burden, to Washington Headquarters Services, Directorate for Information Operations and Reports, 1215 Jefferson Davis Highway, Suite 1204, Arlington, VA 22202-4302, and to the Office of Management and Budget, Paperwork Reduction Project (0704-0188), Washington, DC 20503.

\begin{tabular}{|l|c|c|}
\hline 1. AGENCY USE ONLY (Leave blank) & $\begin{array}{c}\text { 2. REPORT DATE } \\
\text { June } 1994\end{array}$ & $\begin{array}{r}\text { 3. REPORT TYPE AND DATES COVERED } \\
\text { Technical Memorandum }\end{array}$
\end{tabular}

\section{TITLE AND SUBTITLE}

Measurement of the Coolant Channel Temperatures and Pressures of a Cooled Radial-Inflow Turbine

6. AUTHOR(S)

L. Danielle DiCicco, Brent C. Nowlin, and Lizet Tirres

7. PERFORMING ORGANIZATION NAME(S) AND ADDRESS(ES)

National Aeronautics and Space Administration

Lewis Research Center

Cleveland, Ohio 44135-3191

9. SPONSORING/MONITORING AGENCY NAME(S) AND ADDRESS(ES)

National Aeronautics and Space Administration

Washington, D.C. 20546-0001
5. FUNDING NUMBERS

WU-505-62-10
8. PERFORMING ORGANIZATION REPORT NUMBER

E-8866

10. SPONSORING/MONITORING AGENCY REPORT NUMBER

NASA TM-106594

AIAA-94-2561

11. SUPPLEMENTARY NOTES

Prepared for the 18th AIAA Aerospace Ground Testing Conference sponsored by the American Institute of Aeronautics and Astronautics, Colorado Springs, Colorado, June 20-23, 1994. L. Danielle DiCicco and Brent C. Nowlin, NASA Lewis Research Center and Lizet Tirres, NYMA, Inc., Engineering Services Division, 2001 Aerospace Parkway, Brook Park, Ohio 44142 (work funded by NASA Contract NAS3- ). Responsible person, L. Danielle DiCicco, organization code 2840, (216) 433-5656.

\section{2a. DISTRIBUTION/AVAILABILITY STATEMENT}

\section{2b. DISTRIBUTION CODE}

Unclassified - Unlimited

Subject Category 07

\section{ABSTRACT (Maximum 200 words)}

Instrumentation has been installed on the surface of a cooled radial-inflow turbine. Thermocouples and miniature integrated sensor pressure transducers were installed to measure steady state coolant temperatures, blade wall temperatures, and coolant pressures. These measurements will eventually be used to determine the heat transfer characteristics of the rotor. This paper will describe the procedures used to install and calibrate the instrumentation, and the testing methods followed. A limited amount of data will compare the measured values to the predicted values.

\section{SUBJECT TERMS}

Turbine; Turbine cooling; Pressure measurement; Temperature measurement

15. NUMBER OF PAGES

17. SECURITY CLASSIFICATION OF REPORT Unclassified

\section{SECURITY CLASSIFICATION OF THIS PAGE Unclassified}

19. SECURITY CLASSIFICATION
OF ABSTRACT
Unclassified
19. SECURITY CLASSIFICATION Unclassified

A03

20. LIMITATION OF ABSTRACT 